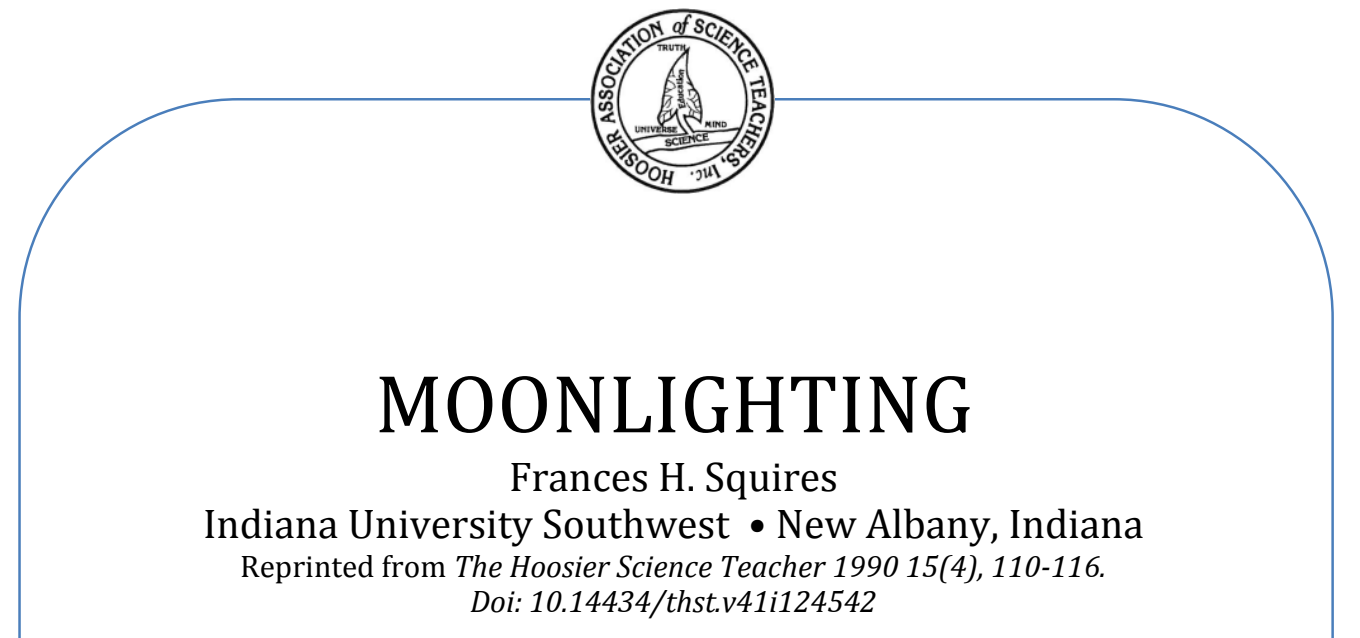

An activity (a simulation of the moon's cycle) may help explain to elementary school children the reasons why we see the moon at different times of the day and in different parts of the sky. The activity may also be used to demonstrate moon rise, moon set, and the phases of the moon.

\title{
Preparation Stage
}

1. Mark a large "magic circle" on the floor with twenty-eight spaces, one for each day of the "moonth." (See Figure 1.)

2. Cut out a large yellow circle for the student who will be the "sun" to pin on the front of his/her shirt.

3. Cut out two smaller circles of the same size, one white and one black, to represent the "moon" and its "shadow."

4. Make a sign with a map of the United States on the sign for the "earth" to pin on his/her shirt. A silhouette will do. It is easy for the students to remember that the sun rises first on the New York side of the country and sets on the California side.

5. Make two signs to pin on the shoulders of the "earth". The left shoulder should have the sign that says "East" and the right shoulder should have the sign that says "West".

6. Assign students to stand in place around the "magic circle."

7. Assign one student (representing the earth) to stand in the center of the circle and one student (representing the sun) to stand outside the circle. The "earth" and "sun" should line up with the first position of the circle which is the new moon and the opposite position in the circle, the full moon. 


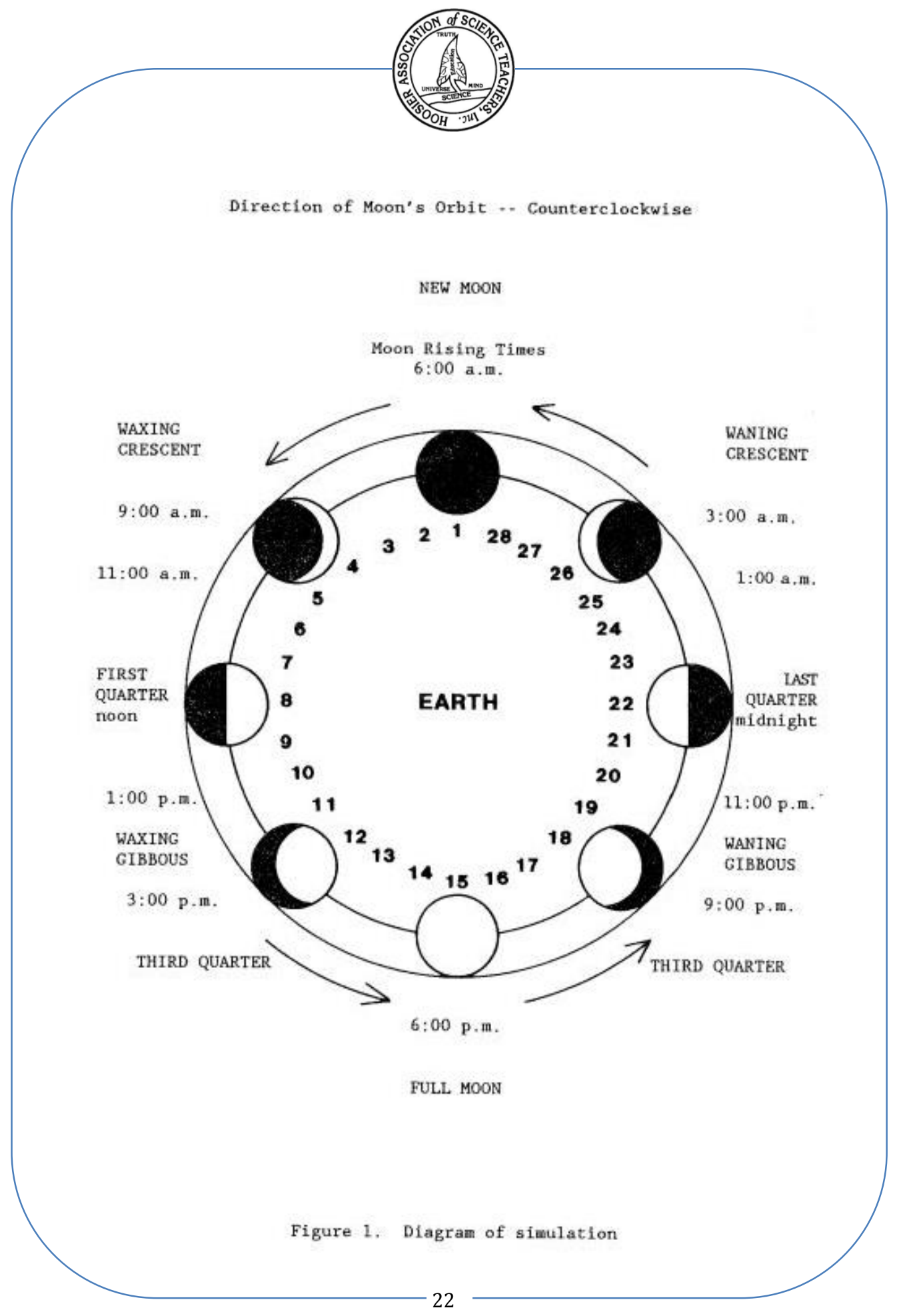




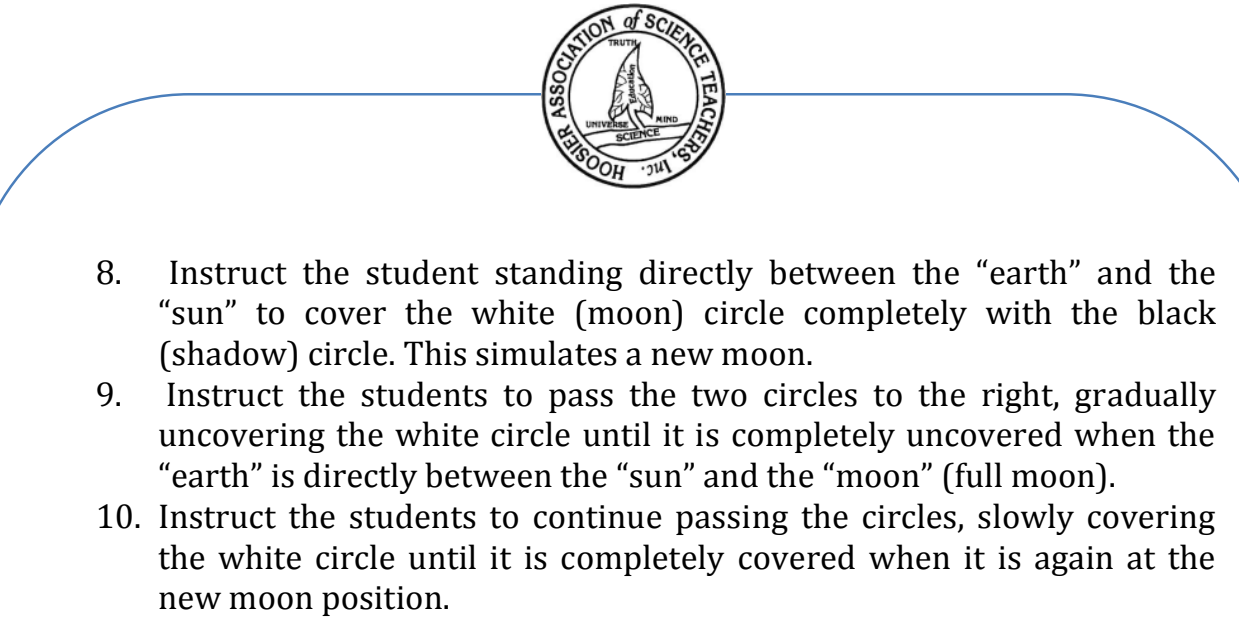

This activity enables the students to notice that first the moon seems to become larger (wax) and then seems to become smaller (wane). (The students should practice uncovering and covering the white circle. They should also practice passing the "moon" and the "shadow" around the "magic circle" counterclockwise or to the right to become familiar with the moon's cycle. The concept illustrated by this activity is a very difficult time/space relationship for children to learn.)

The Game Plan

A small disc or ball representing the moon is passed around the "magic circle" as each "day" or "night" occurs. The student representing the earth stands in the center of the circle and turns counterclock-wise once for every day in the "moonth." The student representing the sun stands outside the circle a short distance, lined up with the earth and the first day of the "moonth."

Students should be arranged in the circle and assigned phases of the moon. The new moon is between the sun and the earth. The full moon is on the opposite side of the circle in a direct line with the new moon. Half moons are directly opposite each other, halfway between the positions of new moon and the full moon on the circle; students representing first and last quarters should be opposite each other.

\section{The Rules -- Just the Facts, Ma'am}

Instruct the students that the moon moves counterclockwise around the earth starting with the new moon. Since the number of students you have may not fill the twenty-eight spaces for all of the days of the "moonth," you may wish to 


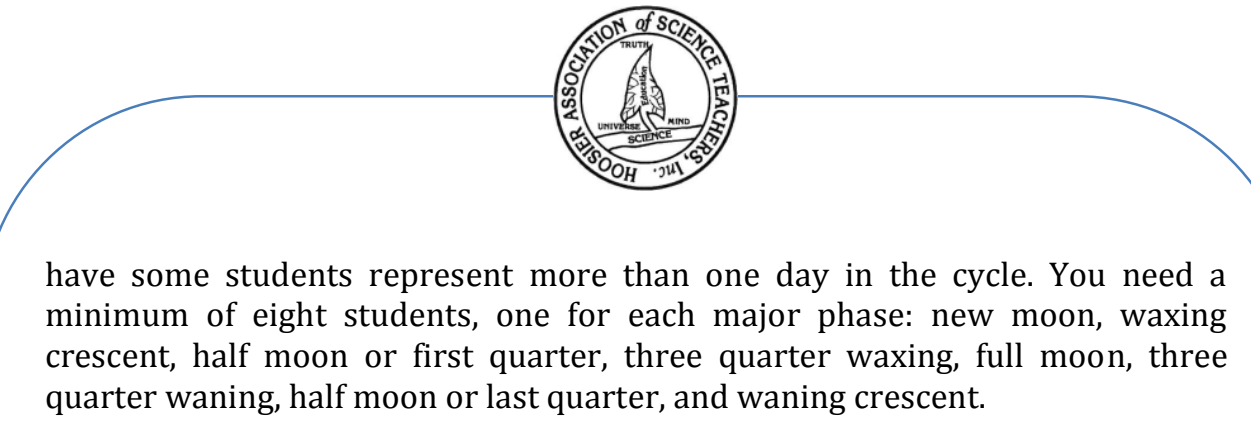

Instruct the students to notice where the moon is in relation to the sun and the earth as each "day" and "night" passes on the earth. The "earth" may begin turning counterclockwise using the left shoulder as the eastern horizon where the sun "comes up" and the right shoulder as the western horizon where the sun "goes down." Of course you will need to explain that sunrise and sunset are caused by the rotation of the earth on its axis and that, while it looks like the sun is moving across the sky, in reality it is the earth that is moving. This is quickly demonstrated in the "magic circle" that we have created.

Now ask the student who is representing the earth to tell what he/she sees in the "sky" directly in front of him/her as the "sun" rests over his/her left shoulder when the "moon" is in the first position or new moon. The answer should be both the sun and the moon are rising.

(And when the sun sets, the moon will also set.) During the day, both the sun and the moon are in the same part of the sky. The sun is lighting up the back of the moon which we cannot see so we do not see the new moon during the day. And since the new moon is up during the day, we do not see the new at night.

These facts should be pointed out to the students and demonstrated more than once. The "earth" should be required to turn on his/her axis several times showing the sunrise and sunset. Also, the fact that during the day as the earth faces the sun and the moon, the back of the earth (represented by the back of the student) is having night and, of course, neither the sun nor the moon is visible.

\section{Play Ball}

The students representing the phases of the moon should be seated on the floor facing the "earth" and rise when it is time to "shine." Thus, the only student in the circle to be standing, when the new moon is rising and setting, is the student in the first position in the circle holding the disc used to represent the moon. The student stands and states the phase of the moon and the rising and setting times. For example, the new moon student will say, "I am the new moon; 


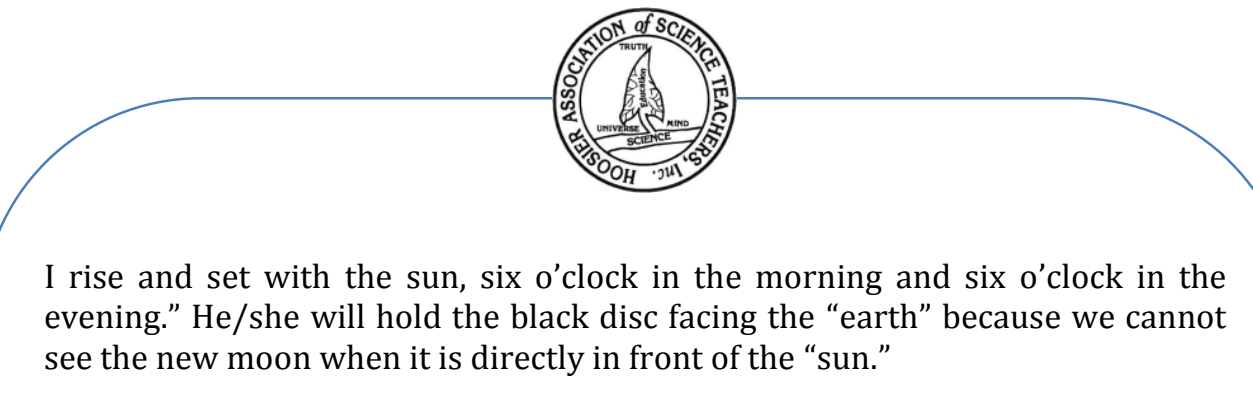

The new moon student passes the disc, or moon, to the next student in the circle to his/her right (counterclockwise). This student stands, adjusts the disc so that a tiny sliver of white shows, and says, "I am the waxing crescent; I rise shortly after sunrise, about seven o'clock in the morning and I set about an hour after sunset or seven in the evening." This starts the waxing phase of the moon. (Waxing means to grow. larger.) The students continue in like fashion around the circle. The waxing crescent is not usually visible during the day because it is so close to the sun. However, after the sun sets, a slice of the moon is visible for a little while in the western sky. Soon, however, the moon also sets so there is no moon visible during the rest of the night.

Continue to have the students pass the moon disc around the circle, standing when it is his/her turn. As each student sits down another "day" and "night" have passed, the "earth" has rotated one more time. If you standardize the time of sunrise at six a.m. and the sunset at six p.m., you can have the positions of the moon vary by almost one hour each day. For example, if the sun comes up at six a.m. on the second day of the lunar month, then the moon comes up at seven a.m. On the third day, the moon comes up at eight a.m. and on the fourth day, at nine a.m. This is not perfect because there are fourteen positions on each side of the circle and only twelve hours on the clock. The actual variation from day to day is closer to SO minutes than 60 minutes. Point out that this is only a simulation.

\section{$\underline{\text { Scoring Points }}$}

As the moon moves around the "magic circle," your students will discover that the moon comes up later and later in the day and sets later and later during the night until the full moon on the fifteenth night. In this position, the sun and the moon have opposite rising and setting times. When the sun comes up, the moon goes down. And conversely when the sun sets, the moon rises. On the second half of the circle, the students will discover that the moon is rising later and later during the night and setting during the day. Another thing to note is that the moon rises in the east just as the sun rises in the east. The moon sets in the 


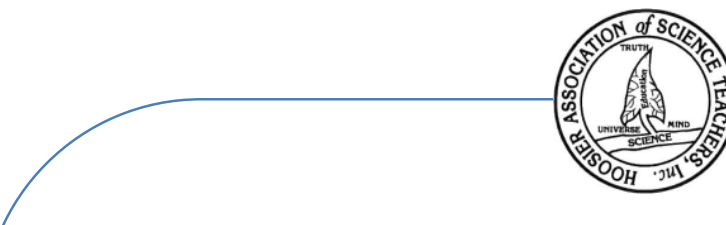

west, again like the sun, and of course, both phenomena are the result of the earth's rotation on its axis.

A conclusion your students should be able to draw (with a little help from you) is that, if you see the moon in the west, it is setting and, if you see the moon in the east, it is rising. The moon seen in the morning in the west is setting and it is also waning. The moon seen in the west in the afternoon is waxing.

You will probably have to do this simulation several times to help the students visualize what is happening. It will be helpful to have the students keep track of the moon for at least a month before you start the lesson and discussion. It is also helpful to continue making observations of the moon for another month after the lesson. The students may use Figure 2 to record their data.

\section{$\underline{\text { Extensions }}$}

The newspaper prints the time of sunrise, sunset, moonrise and moonset. You may wish to collect these data for a month to help your observation since there will be days that the moon is not visible at the times you will be recording data.

Hopefully this simulation will lead to discussions of many other related topics. For example: how and why the tides are affected by the moon, lunar eclipses and solar eclipses, time zones, the seasons, traveling to the moon in a spacecraft, and what the earth looks like from the moon. Happy discovering!

\section{$\underline{\text { References }}$}

1. Comstock, Anna Botsford. Handbook of Nature Study, Twenty-Fourth Edition. Cornell University Press. Ithaca, New York. 1978.

2. Guiness, Alma E., Editor. Joy of Nature. Reader's Digest Association. Pleasantville, New York. 1977.

3. Harvey, Edmond J., Editor. Reader's Digest Book of Facts. Reader's Digest Association. Pleasantville, New York. 1987.

4. Scheffel, Richard L. ABC's of Nature -- A Family Answer Book. Reader's Digest Association. Pleasantville, New York. 1984. 


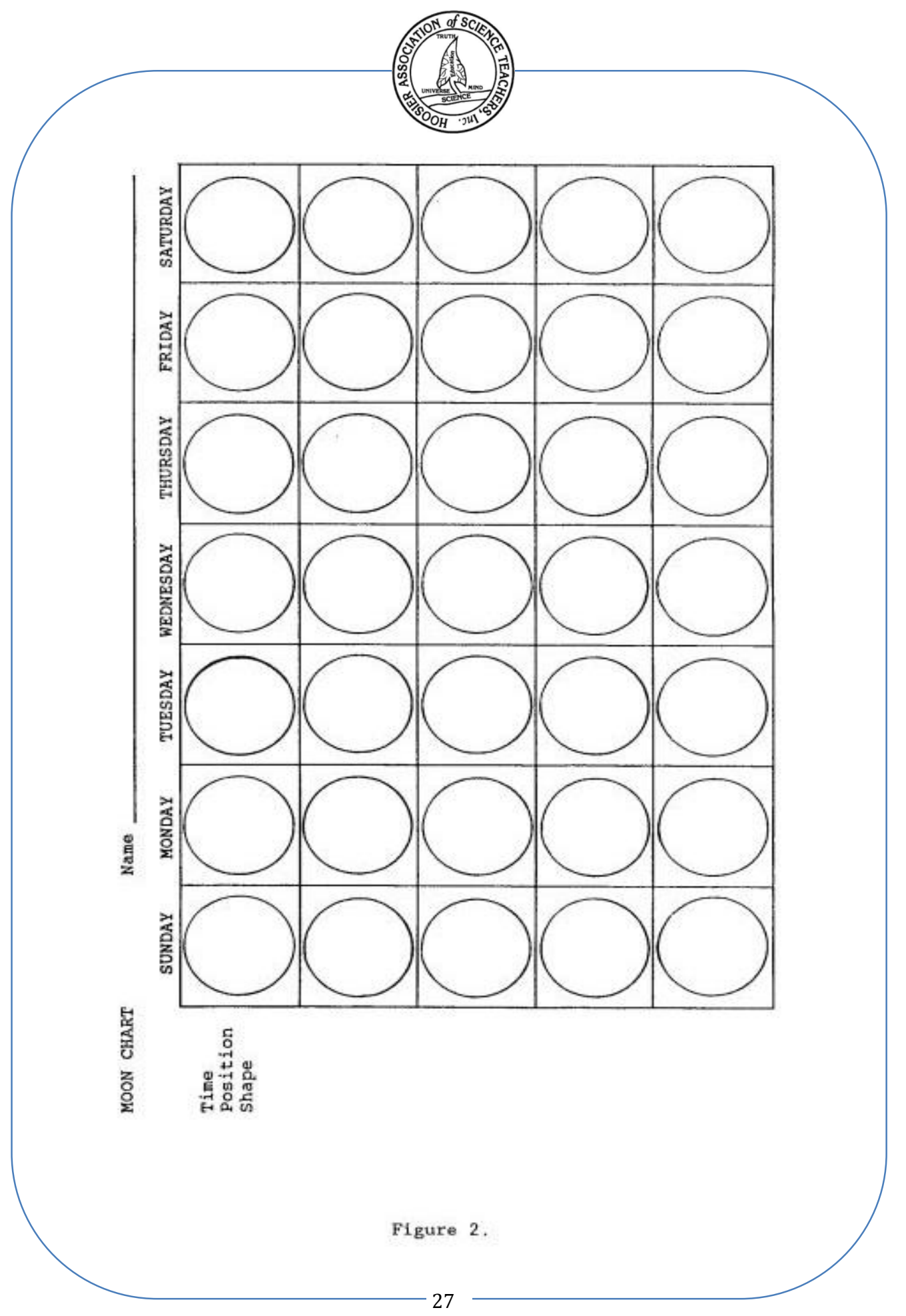


ADDENDUM - - MOON FACTS

1. The moon shines by reflected light. That is, we see the moon be- cause the sun's light bounces off of the moon's surface and back to earth.

2. The moon revolves around the earth once in 29 days. We call this a month.

3. The moon rotates once on its axis every 27 days 7 hours and 43 minutes. This is also called a month.

4. Since the moon rotates on its axis once a month we are seeing the same side of it all the time.

5. The moon appears to wax or grow in size to full moon then wane or

6. Starting with the moon in the position in its orbit directly between the earth and the sun, the phases are as follows:

New Moon

Waxing Crescent

First Quarter (also called the half moon)

Waxing Gibbous (or three quarter moon)

Full moon

Waning Gibbous (or three quarter moon)

Last Quarter (also called the half moon)

Waning Crescent

7. The moon moves in its orbit counterclockwise around the earth.

8. The moon is approximately 240,000 miles from the earth.

9. The diameter of the moon is 2,160 miles, or about one-fourth of the earth's diameter.

10. The moon has neither air nor water on its surface. (It does however have a lot of foot prints and a flag.)

\section{APA reference for this reprinted article:}

Squires, F. H. (1990). Moonlighting. The Hoosier Science Teacher. 15(4), 110-117. Doi: $10.14434 /$ thst.v41i124542 